\title{
$\mathrm{SnO}_{2} @ \mathrm{C}$ composite as Anode Material of Lithium-ion Batteries with Enhanced Cycling Stability
}

\author{
Li-lai Liu ${ }^{1,2,3, *}$, Ming-yang $\mathrm{Li}^{1}$, Yi-han Sun ${ }^{1}$, Min-xuan Ma ${ }^{1}$, Xue-ying Yang ${ }^{1}$, Hui Wang ${ }^{1}$ \\ ${ }^{1}$ College of Environmental and Chemical Engineering, Heilongjiang University of Science and \\ Technology, Harbin 150022, China \\ ${ }^{2}$ School of Chemical Engineering and Technology, Harbin Institute of Technology, Harbin, 150001, \\ China \\ ${ }^{3}$ Baotailong new materials co. LTD., Jixi 158100, China \\ *E-mail: 11lusth@163.com
}

Received: 16 September 2021 / Accepted: 1 November 2021 / Published: 2 February 2022

The $\mathrm{SnO}_{2} @ \mathrm{C}$ composite was prepared by a two-step microwave-hydrothermal method using a microwave reaction system. The surface of the carbon spheres is composited of the $\mathrm{SnO}_{2}$ nanoparticles with a diameter of about $3 \mathrm{~nm}$. The $\mathrm{SnO}_{2} @ \mathrm{C}$ composite exhibits excellent electrochemical performances in lithium-ion batteries. The first discharge/charge capacities at a current density of 700 and $1000 \mathrm{mAg}^{-}$ ${ }^{1}$ is $1393 / 766$ and $1309 / 685 \mathrm{mAh} \cdot \mathrm{g}^{-1}$ with coulomb efficiencies of $54.99 \%$ and $52.33 \%$, respectively. Even after 100 cycles, the discharge specific capacities at a current density of $1000 \mathrm{mAg}^{-1}$ remains 480 $\mathrm{mAh} \cdot \mathrm{g}^{-1}$ with coulomb efficiencies of $99.40 \%$.

Keywords: $\mathrm{SnO}_{2}$, microwave-hydrothermal, lithium-ion batteries, carbon spheres, electrochemical performances

\section{FULL TEXT}

(C) 2022 The Authors. Published by ESG (www.electrochemsci.org). This article is an open access article distributed under the terms and conditions of the Creative Commons Attribution license (http://creativecommons.org/licenses/by/4.0/). 